\title{
Propofol pharmacology in patients with brain tumours
}

\author{
M.M. Sahinovic, D. Eleveld, M.M.R.F. Struys, A.R. Abs alom \\ De partment of Ane s the siology, Unive rs ity of Groningen, Unive rs ity Me dical Cente $r$ \\ Groningen, The Ne the rlands
}

\section{Background and Goal of the Study:}

PK/PD models developed in patients without brain pathology are widely used for target controlled infusion (TCI) of propofol during brain tumour excision operations. Although some animal and patient studies suggest that brain tumours and associated treatments alter the pharmacokinetics (PK) and pharmacodynamics (PD) of the anaesthetic drugs, the evidence is conflicting. The goal of this study was to determine if the presence of a frontal brain tumour influences propofol pharmacokinetics and dynamics and PK/PD model performance.

\section{Material and Methods: Twenty patients with} a frontal brain tumour and 20 control patients received a propofol infusion to achieve an "induction ${ }_{1}$-emergenceinduction $_{2}$ "anaesthetic sequence. No opioids were administered. Arterial propofol plasma concentration was measured every 4 minutes and at each of the transitions of conscious state. These measurements and continuously recorded BIS values were analysed by nonlinear mixed effects modelling to generate a new PK and a PD propofol model. We investigated the effect of different model adaptations on PK and PD performance.

Subsequently we back-calculated the propofol concentrations predicted by the Marsh, Schnider and Eleveld models, and calculated the predictive performance of these models in terms of the Varvel criteria i.e in terms of median prediction error $(M d P E)$ and median absolute prediction error (MdAPE).

\section{Results and Discussion: Hierarchical PK model} development resulted in a three-compartment allometric model scaled to total-body-weight. (see table 1). Patients with brain tumours showed $40 \%$ higher propofol clearance than control patients. (see figure 1). In patients with brain tumours, MdPEpk was $-3.83 \%$, and MdAPEpk 21.1\%. Predictive performance of the Schnider model (MdPEpk-20.0\%, MdAPEpk 23.4\%) and Eleveld volunteer model (MdPEpk-8.58\%, MdAPEpk 21.6\%) were good. The Marsh model performed less well (MdPEpk-14.3\%, MdAPEpk 41.4\%) as did the Eleveld patient model (MdPEpk $30.8 \%$, MdAPEpk 32.1\%).

Hierarchical PD model development found that $k e 0$ (0.108 min-1), Ce5O $(2.77 \mathrm{ml} / \mathrm{l})$ and the $\gamma(1.49)$ did not significantly differ between the two groups. Lower baseline BIS value were found in patients with brain tumours (90.2 vs 95.1).

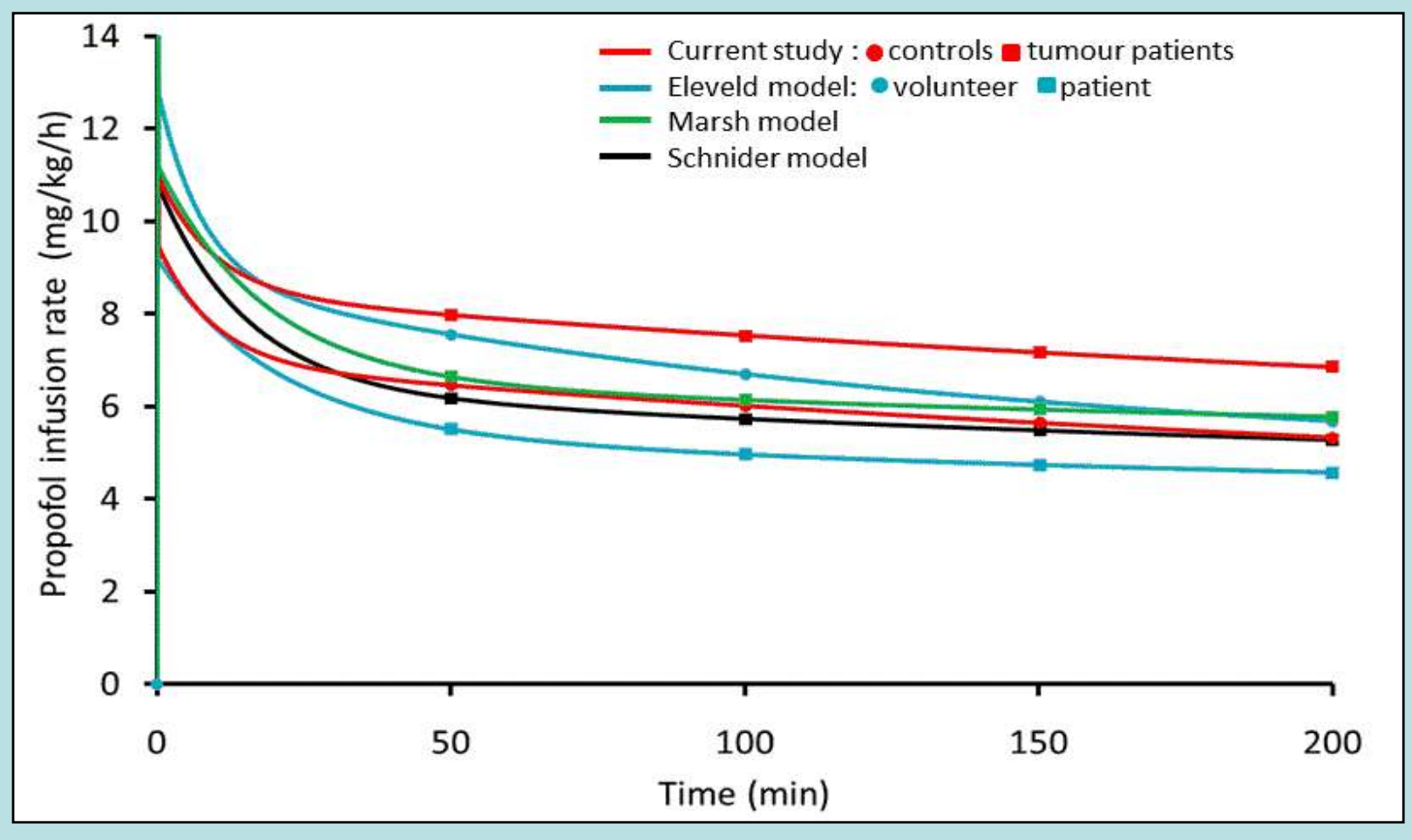

Figure 1. Simulated propofol infusion rates necessary to achieve and maintain propofol plasma concentration of 3 $\mu \mathrm{g} / \mathrm{ml}$ according to different pharmacokinetic propofol models in a 35 year old male, height $170 \mathrm{~cm}$, weight $70 \mathrm{~kg}$.

\begin{tabular}{|c|c|c|c|c|c|c|c|}
\hline Pharmacokinetic equations & Parameter $(\mathbf{L})$ & $\begin{array}{l}\text { Estimated } \\
\text { value }\end{array}$ & \multicolumn{2}{|c|}{$\begin{array}{l}\text { 95\% CL } \\
\text { Lower Upper }\end{array}$} & \multicolumn{2}{|r|}{ Variance $(\omega 2)$} & $\mathrm{CV}(\%)$ \\
\hline$S I Z E=(W G T / 70 \mathrm{~kg})$ & V1ref (L) & 3.80 & 3.08 & 4.54 & $\eta 1$ & 0.205 & 47.8 \\
\hline$K_{\text {tamar }}=\left\{\begin{array}{ll}1, & \text { control } \\
1\end{array}\right\}$ & V2 ref $(L)$ & 9.21 & 5.50 & 13.1 & $\eta 2$ & 0.268 & 55.5 \\
\hline$V 1(l) \quad=V 1_{r e f} \cdot S I Z E \cdot \exp (\eta 1)$ & $V 3 \operatorname{ref}(L)$ & 447 & 92.6 & 1930 & $\eta 3$ & 0.009 & 9.52 \\
\hline$V 2(l) \quad=V 2_{r f f} \cdot S I Z E \cdot \exp (\eta 2)$ & CL ref $(\mathrm{L} / \mathrm{min})$ & 1.33 & - & 2.21 & $\eta 4$ & 0.192 & 46.0 \\
\hline$V 3(l) \quad=V 3_{r e f} \cdot S I Z E$ & Q2 $\operatorname{ref}(\mathrm{L} / \mathrm{min})$ & 0.987 & 0.775 & 1.20 & $\mathbf{R E}$ & 0.191 & \\
\hline$C L\left(I \cdot \min ^{-1}\right)=C L_{r e f} \cdot S I Z E^{0.75} \cdot K_{\text {tamar }} \cdot \exp (\eta 3)$ & Q3 ref $(\mathrm{L} / \mathrm{min})$ & 1.37 & 0.379 & 2.79 & & & \\
\hline $\begin{array}{l}Q 2\left(l \cdot \min { }^{-1}\right)=Q 2_{r e f} \cdot\left(V 2 / V 2_{r e f}\right)^{0.76} \\
Q 3\left(l \cdot \min ^{-1}\right)=Q 3_{r e f} \cdot\left(V 3 / V 3_{r e f}\right) \cdot \exp (\eta 4)\end{array}$ & $\Theta 1$ & 0.444 & 0.201 & - & & & \\
\hline
\end{tabular}

Table 1: PK equations and parameter values

Conclusion: Frontal brain tumours are associated with differences in the pharmacokinetics and pharmacodynamics of propofol. Caution and good clinical judgment should be exerted when using current propofol TCI in patients with frontal brain tumours. 